\title{
Teste de percepção tátil e térmica com materiais têxteis utilizados em uniformes
}

\section{Tatiana Castro Longhi}

Doutoranda, Universidade do Estado de Santa Catarina/ dilonghi@gmail.com Orcid: 0000-0002-7391-9566 / lattes

Eugenio Andrés Díaz Merino

Doutor, Universidade Federal de Santa Catarina / eugenio.merino@ufsc.br Orcid: 0000-0002-7113-6031 / lattes 


\title{
Teste de percepção tátil e térmica com materiais têxteis utilizados em uniformes
}

\begin{abstract}
RESUMO
Os uniformes profissionais são usados para padronizar os usuários durante toda a jornada de trabalho, e seus materiais têxteis ficam em contato direto com a pele. Entretanto, este tipo de vestuário muitas vezes é adquirido em grande quantidade e são feitos em materiais têxteis economicamente viáveis para os empregadores. Quando o conforto não é prioridade, o usuário pode ser prejudicado com o uso prolongado das peças. Este artigo investiga a percepção do usuário a respeito do conforto tátil, que vem a ser o toque do tecido na pele, e a percepção térmica ou sensação de calor ou frio provocada pela amostra têxtil. 0 teste de campo foi feito com 20 participantes utilizando-se cinco amostras de têxteis comumente empregados em camisas, camisetas e calças de uniformes de serviços gerais e uma de vestuário esportivo. As amostras foram testadas aos pares, entre tecidos planos e malhas. Os resultados indicam a preferência dos participantes pelo tecido esportivo por este ser mais macio e fresco ao toque na pele.
\end{abstract}

Palavras-chave: conforto. Materiais têxteis. Uniformes. 


\title{
Tactile and thermal perception test with textile materials used in uniforms
}

\begin{abstract}
Workwear is worn to standardize wearers throughout the workday, and their textile materials come in direct contact with the skin. However, this type of clothing is often purchased in large quantities and are made of economically viable textile materials for employers. When comfort is not a priority, the user may be adversely affected by prolonged use of parts. This article investigates the user's perception of tactile comfort, which is the touch of the fabric on the skin, and the thermal perception or sensation of heat or cold caused by the textile sample. The field trial was conducted with 20 participants using five textile samples commonly used on shirts, T-shirts, and trousers for general service workwear and one for sportswear. Samples were tested in pairs between flat and knitted fabrics. The results indicate the participants' preference for sportswear because it is softer and fresher to the skin.
\end{abstract}

Keywords: comfort. Textile materials. Workwear. 


\title{
Prueba de percepción táctil y térmica con materiales textiles utilizados en uniformes de servicios generales.
}

\begin{abstract}
RESUMEN
Los uniformes profesionales se utilizan para estandarizar a los usuarios durante toda la jornada laboral, y sus materiales textiles están en contacto directo con la piel. Sin embargo, este tipo de ropa a menudo se compra en grandes cantidades $y$ está hecha de materiales textiles económicamente viables para los empleadores. Cuando la comodidad no es una prioridad, el usuario puede verse perjudicado por el uso prolongado de las piezas. Este artículo investiga la percepción del usuario de la comodidad táctil, que es el tacto del tejido sobre la piel, y la percepción térmica o sensación de calor o frío causada por la muestra textil. La prueba de campo se realizó con 20 participantes utilizando cinco muestras de textiles comúnmente usados en camisas, camisetas y pantalones con uniformes de servicio general y uno en ropa deportiva. Las muestras se analizaron en pares, entre telas planas y mallas. Los resultados indican la preferencia de los participantes por la tela deportiva porque es más suave y fresca cuando se toca la piel.
\end{abstract}

Palabras clave: confort. Materiales textiles. Uniformes. 


\section{INTRODUÇÃO}

O conforto é um conceito de difícil definição e que suscita diversas investigações. Menegon (2013) afirma que o conforto é um dos objetivos da ergonomia, durante a interação entre o ser humano e um objeto, esse fenômeno subjetivo ocorre em alguma medida, relacionando-se simultaneamente com o ambiente e o contexto. Assim, a ergonomia ou os fatores humanos buscam entender o que faz o ser humano sentir o equilíbrio das suas funções, o que vem a resultar na ausência de desconforto.

A homeostase humana, que vem a ser o equilíbrio das funções fisiológicas, é um indício de conforto físico. Por outro lado, a dor ou a sensação de peso indicam o desconforto do indivíduo (MENEGON, 2013). O impacto das sensações positivas ou negativas que sugerem $\mathrm{o}$ conforto ou $\mathrm{o}$ desconforto também varia entre os indivíduos, que podem ser extremamente sensíveis ou extremamente resistentes às condições que modificam os estados de conforto.

O vestuário é um produto utilizado diariamente pelos indivíduos em contato direto com a pele, o que torna a sensação de conforto essencial numa peça. Nesse sentido, os materiais têxteis desempenham um papel crucial, pois além de ser uma barreira entre o corpo e o ambiente, provocam sensações térmicas e táteis advindas desse contato. Para Monteiro (2009), do ponto de vista dos fatores humanos, no que tange a roupas para o desenvolvimento de atividade física, seja ela laboral ou desportiva, é papel do designer garantir o conforto durante 0 uso. Outros profissionais também contribuem para a definição das características dos materiais têxteis, tais como engenheiros têxteis e de materiais. 
No caso da atividade laboral, a movimentação do usuário aumenta a temperatura corporal. Aliado a um ambiente externo de temperatura de normal a elevada, a tendência é de que o vestuário prejudique a sensação de conforto térmico. O conforto tátil do material também pode interferir no desempenho do usuário, uma vez que o material pode ser fresco, mas também apresentar alguma aspereza ao tocar a superfície da pele.

Segundo LaBat (2006), os campos de design de vestuário variam de design de moda a design de roupas de proteção, na qual combina-se moda e funcionalidade. A maioria dos designers de moda se concentra em elementos visuais do produto e o funcionamento físico do vestuário no corpo não é uma consideração importante. Novos paradigmas na educação de design de vestuário enfatizam o design baseado em pesquisa que incorpora fatores humanos como um dos principais focos da atividade de design em todos os campos, da moda para a função prática. Designers de vestuário que incorporam fatores humanos em seu processo de design consideram todos os elementos físicos de um design que afetam o conforto tátil, a visibilidade, as limitações físicas e o equilíbrio térmico da pessoa. As necessidades psicológicas e sociais são frequentemente abordadas com elementos visuais do design, enquanto os elementos materiais e a forma são desenvolvidos para atender às necessidades físicas do usuário (LABAT, 2006).

$\mathrm{Na}$ atividade desportiva os avanços alcançados na tecnologia dos tecidos são aplicados no vestuário. Nos uniformes, porém, frequentemente os materiais têxteis utilizados não sofrem a mesma renovação. Tecidos como a sarja e o brim são utilizados em uniformes de serviços gerais devido a sua resistência à abrasão; camisetas em meia malha de algodão ou poliviscose devido a sua praticidade e 
seguem os exemplos. Porém, em todos os casos, o preço de venda do produto no comércio muitas vezes é o fator que determina a escolha da empresa. Naturalmente existem companhias que adquirem produtos de qualidade superior com características que evitam o desconforto do usuário ao minimizar o suor, garantir a maciez do toque, utilizar fibras que evitam desconforto térmico etc. Porém, muitas empresas evitam esse tipo de gasto. Assim, uniformes são comprados em grandes quantidades e com foco no custo e não no conforto e desempenho do usuário.

O conforto é um item de difícil mensuração, pois é entendido de modo diferente de pessoa para pessoa e muitas vezes não é uma preocupação que determine a escolha das peças. Entretanto, o usuário durante a jornada em que está vestido de uniforme, também requer liberdade de movimentos, conforto tátil e térmico proporcionado pelo vestuário. O uso de materiais têxteis desenvolvidos para a prática esportiva na concepção de uniformes profissionais pode ser uma alternativa a fim de proporcionar melhor conforto e desempenho aos usuários.

\section{Efeitos fisiológicos do calor e a atividade física}

De acordo com Iida (2005), os seres humanos suportam bem as diferenças climáticas em função da ausência de pelos no corpo e da existência das glândulas sudoríparas. A termorregulação humana é o que torna o homem um animal homeotérmico. Sua temperatura interna mantém-se em torno de $37^{\circ} \mathrm{C}$, com oscilação considerada normal para \pm $2^{\circ} \mathrm{C}$, ou seja, entre 35 a $39^{\circ} \mathrm{C}$. O corpo humano gera calor continuamente pelo processo de combustão, durante o qual os açúcares, gorduras e proteínas são usados como combustíveis, que ao serem consumidos pelo oxigênio, 
liberam gás carbônico e água. 0 excedente é eliminado pelo suor, através dos mecanismos de sudação. Além disso, há também contínuas trocas de calor com o ambiente circundante, que ocorrem por meio dos processos de condução, convecção e irradiação.

A sensação térmica dos seres humanos está relacionada principalmente ao equilíbrio térmico do corpo como um todo, ou seja, quando a produção interna de calor no corpo é igual à perda de calor para o ambiente (TOFTUM, 2005). A evaporação é o mecanismo mais importante do equilíbrio térmico, que ocorre nos pulmões e na superfície da pele, sob a forma de suor. É por meio da evaporação do suor que o calor é em parte removido e não pela sua produção (IIDA, 2005).

A produção de calor é determinada pela atividade metabólica. Para um corpo em repouso, representa a quantidade de energia necessária para as funções básicas do corpo. A atividade metabólica aumenta quando o corpo está trabalhando. Quando músculos ativos queimam nutrientes para atividade mecânica, alguma energia é dispensada para fora do corpo, mas a maior parte da energia é liberada internamente como calor. A relação entre este trabalho externo e a energia total consumida é a eficiência com que o corpo realiza o trabalho. A eficiência é quase zero para a maioria das tarefas. No frio, os tremores podem produzir calor adicional, aumentando a taxa metabólica e a produção de calor em até quatro vezes (HAVENITH, 2005).

A avaliação feita por meio da troca de calor requer a medição dos parâmetros climáticos que afetam o balanço de calor humano (Figura 1). Para conforto ou baixa tensão térmica, este balanço deve estar próximo do equilíbrio (a produção de calor equivale à perda de calor), resultando em 
uma temperatura corporal relativamente estável (HAVENITH, 2005).

Figura 1. O balanço de calor é a soma de todas as perdas e ganhos de calor do corpo.

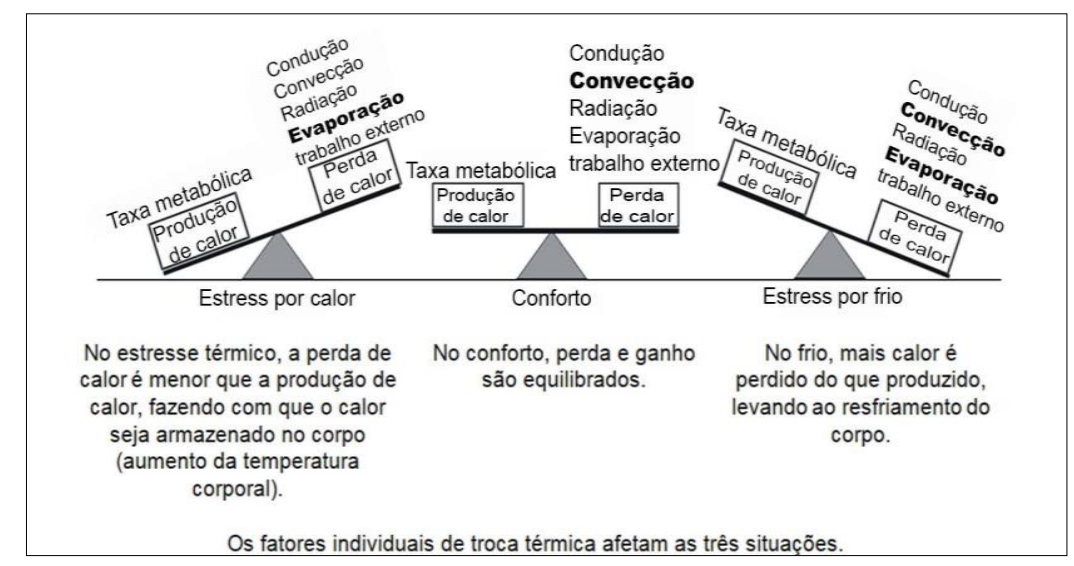

Fonte: Havenith (2005, p. 471).

A atividade física de qualquer natureza eleva naturalmente a sensação térmica do corpo, em maior ou menor medida em relação ao ambiente externo. De acordo com Iida (2005), o trabalho físico muito pesado, em condições externas desfavoráveis pode provocar um desequilíbrio térmico, aumentando a temperatura corporal. Grandjean (1998) elenca os quatro fatores climáticos e de conforto, que influenciam as trocas de calor: temperatura do ar, temperatura das superfícies limitantes, umidade do ar, movimentação do ar.

Uma situação ideal é aquela na qual a tempera pode ser regulada de acordo com a preferência do indivíduo, uma vez que a sensação de conforto climático varia entre as pessoas. Isso é possível em ambientes fechados, como escritórios, mas torna-se inviável em ambientes externos. Na execução de trabalhos pesados, o ambiente mais frio é mais favorável, enquanto nos leves o clima mais quente é mais agradável. Como não é possível controlar o clima externo, deve-se 
adaptar o gasto energético às tarefas que precisam ser executadas ao ar livre. Assim, tarefas pesadas devem ser executadas em temperaturas mais frias. No caso de climas mais quentes, as tarefas devem ser mais leves e executadas mais lentamente, além de serem intercaladas de pausas, que permitem que o organismo evapore o calor do corpo (DUL; WEERDMEESTER, 1998).

O corpo ganha calor quando a temperatura do ar, a temperatura radiante ou a pressão de vapor ao redor do corpo é maior do que o valor da pele, e isso pode resultar em estresse por calor, como representado na Figura 2 (HAVENITH, 2005).

Figura 2. Vias de perda de calor do corpo.

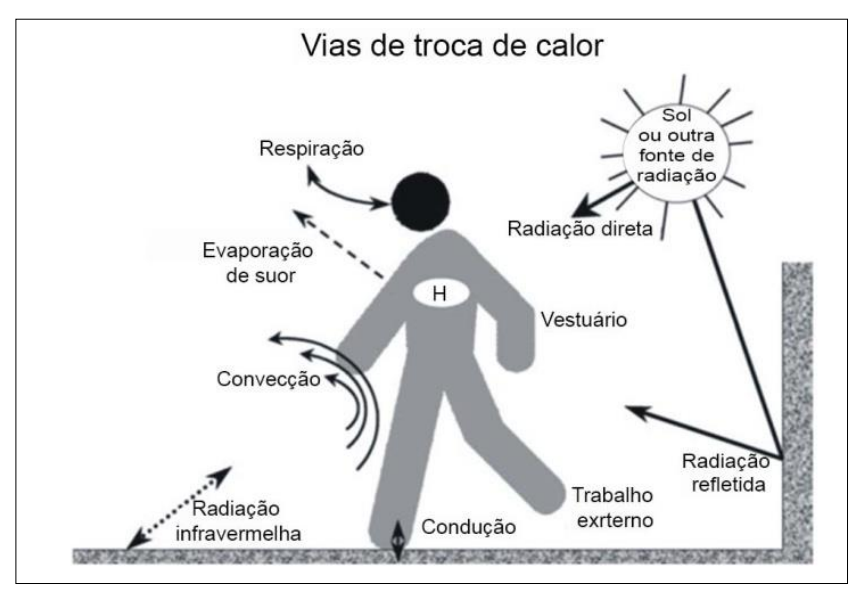

Fonte: Havenith (2005, p. 471).

Para Toftum (2005), para avaliar o conforto térmico, além dos fatores ambientais é preciso considerar as atividades desempenhadas e o vestuário do indivíduo. De um modo geral, uma medida completa de conforto térmico engloba:

- combinação de atividades (intensidade do esforço físico, Iida (2005));

- hábitos de vestuário; 
- parâmetros ambientais:

- temperatura do ar;

- temperatura média radiante (das superfícies limitantes);

- velocidade relativa do ar;

- umidade do ar.

A partir desses dados é possível medir o conforto com base em alguns índices para uma avaliação quantitativa. Um dos índices mais amplamente utilizados é o índice PMV (voto médio previsto). Este índice prevê o valor médio da sensação térmica geral de um grande grupo de pessoas em função da atividade (taxa metabólica), isolamento da roupa e os quatro parâmetros ambientais: temperatura do ar, temperatura radiante média, velocidade do ar, e umidade do ar (FANGER, 1970 apud TOFTUM, 2005). O índice PPD (porcentagem prevista de insatisfação) é derivado do índice PMV e prevê a porcentagem de pessoas termicamente insatisfeitas entre de um grande grupo de pessoas (TOFTUM, 2005).

Diversos autores concordam que a tolerância ao calor varia entre os indivíduos que acabam por se aclimatar às condições ambientais em que se encontram. É também aceito o fato de que a idade e as condições físicas dos indivíduos, bem como a vestimenta imposta pela atividade, como os EPIs no caso do trabalho, impacta fortemente a sensação térmica (SALATA, 2018; TOFTUM, 2005; IIDA, 2005; WISNER, 1987).

\section{O conceito de conforto}

O conforto é o resultado do uso de um determinado produto no qual o usuário experimenta uma condição de bem-estar ou comodidade durante ou depois dessa 
interação. Em função dessa experimentação, o indivíduo tem um papel fundamental na identificação dos aspectos que podem melhorar nos requisitos de conforto (MENEGON, 2013). Isso porque o conforto é um aspecto que só é vivenciado pelo usuário e somente ele pode definir em que medida ele é exigido em cada situação.

O conforto pode ser uma sensação física, um estado psicológico ou ambos simultaneamente. Para a medicina, é "um estado subjetivo de bem-estar em relação a um ambiente induzido, incluindo vibração mecânica ou choque". Conforto não é o mesmo que a ausência de dor, mas diz-se que ele se encontra em um continuum na "dimensão do conforto". Esta dimensão compreende "conforto", "desconforto inconsciente", "desconforto consciente", "fadiga" e "dor". Conforto é um estado positivo, enquanto os outros elementos são sensações cada vez mais negativas (PEARSON, 2009).

Com base nos resultados da correlação entre conforto e desconforto da tese de Menegon (2013) conclui-se que em parte a presença de conforto é a ausência de desconforto; pois nos níveis de Muito a Máximo Conforto há ausência de desconforto e nos níveis de Muito a Máximo Desconforto ocorre ausência de conforto. No entanto, de acordo com a pesquisa nos demais níveis de conforto (mínimo a moderado) há presença de desconforto; assim como nos níveis intermediários do desconforto (mínimo a moderado) há presença de conforto. Outros estudos também indicam que o conforto e o desconforto participam de dimensões diferentes, mas o conforto tende a aumentar quando o desconforto diminui, e vice-versa. (MENEGON, 2013).

De acordo com Grandjean (1998), um clima confortável não é percebido, mas percebemos imediatamente um clima não confortável, quanto mais este se distancia daquele. No 
entanto, não há consenso sobre a natureza dos fenômenos que levam ao conforto e desconforto, o que indica a necessidade de mais pesquisa sobre o assunto (MENEGON, 2013).

Em pesquisa sobre métodos de medição de conforto Pearson (2009), identificou 29 estudos que usam conforto ou desconforto como resultado, nos quais são descritas medidas objetivas e subjetivas. Além da falta de consistência nas medições, foi identificado o uso de uma grande variedade de escalas e ferramentas. Nesta pesquisa, apenas dois instrumentos foram considerados pertinentes. A conclusão indica a necessidade de mais estudos para desenvolvimento e validação de ferramentas de avaliação de conforto para diversas aplicações.

Para Iida (2005) o projeto de vestuário adequado para condições ambientais extremas não é um problema de fácil solução. Roupas isolantes do frio e umidade inibem a transpiração, o que as torna incômodas depois de algum tempo. Aquelas destinadas a proteger contra o calor radiante podem vir a reter o ar junto à pele, que se torna saturado e impede a evaporação do suor. Portanto é uma questão que exige pesquisa e desenvolvimento.

\section{O Conforto nos têxteis}

De acordo com Monteiro (2009), é a Fisiologia do Vestuário que trata da avaliação objetiva da funcionalidade do vestuário de desempenho elevado. Para isso, desde 1992 existe a uma norma, atualmente a ISO 11092:2014 sobre a avaliação fisiológica do vestuário, com um método para determinação de permeabilidade ao vapor de água das estruturas têxteis no estado seco e quanto à sua resistência térmica. 
Os principais requisitos funcionais normalmente esperados em um produto têxtil são: conforto durante o uso; relativa proteção a condições climáticas extremas; proteção da saúde; melhoria do desempenho do desportista; produtos esteticamente agradáveis conforme a moda vigente (MONTEIRO, 2009).

Em sua tese de doutorado Broega (2007), conceitua o conforto relacionado à experiência do usuário com os materiais têxteis, como a ausência de desconforto. 0 desconforto em termos de sensações poderia então ser descrito em termos de quente, frio, áspero, picante etc. Esse estado de neutralidade envolve os estados psicológicos e fisiológicos do indivíduo e podem ser definidos como:

Conforto termofisiológico: ocorre quando o estado térmico e de umidade da superfície da pele são confortáveis porque os materiais têxteis do vestuário permitem a adequada transferência de calor e vapor de água através deles.

Conforto sensorial: ocorre quando um têxtil entra em contato direto com a pele e provoca um conjunto de diversas sensações neurais.

Conforto ergonômico: ocorre quando uma peça de vestuário permite que o usuário movimente livremente o corpo e os membros, usualmente traduzido pela expressão "vestir bem" (SLATER, 1997 apud BROEGA, 2007).

Conforto psicoestético: ocorre quando a percepção subjetiva da avaliação estética - baseada na visão, toque, audição e olfato - é favorável ao usuário.

As percepções subjetivas dos indivíduos envolvem processos psicológicos influenciados por experiências anteriores e desejos atuais. No que tange a percepção sensorial, o fenômeno pode ser observado como as sensações térmicas (frio, quente), sensações relativas à dor 
(áspero, picante) e ao toque (liso, macio, sedoso, rugoso, fofo, fresco) (BROEGA, 2007).

\section{Tipos de materiais têxteis e sua relação com o conforto}

Por sua finalidade de cobrir o corpo e acompanhar seus movimentos as roupas, por meio dos materiais têxteis de que são feitas, desenvolvem o papel de uma segunda camada de pele. Essa camada possui dois lados - o lado externo e o lado interno. O seu lado "direito" (exterior do têxtil), onde se localizam as estampas e bordados, recebe as intempéries do ambiente exterior e em alguma medida as transfere para o usuário. Já o lado "avesso" (interior do têxtil) fica em contato com a pele do usuário e transmite as sensações táteis do material. As condições térmicas do ambiente também são transferidas do exterior para o interior do vestuário. Naturalmente, essas sensações se alteram em função do aquecimento do corpo, provocado por atividade física ou outra alteração metabólica ou psicológica do indivíduo. Segundo Monteiro (2009), o conforto no uso do vestuário é decorrente da combinação entre as características técnicas do produto acabado. Essas características podem ser definidas como a espessura do material, densidade linear (título) do fio, massa por unidade de superfície $\left(\mathrm{g} / \mathrm{m}^{2}\right)$ do produto têxtil, acabamentos presentes no produto, corte e técnicas de confecção.

No que concerne a matéria-prima do vestuário, as fibras têxteis por suas propriedades intrínsecas, podem causar sensações referentes ao toque na pele e a sensação térmica. As fibras de origem natural, obtidas de plantas e de animais, possuem propriedades que são apreciadas por realizarem uma boa troca térmica com o ambiente. No que tange ao 
toque, a maioria das fibras vegetais, excetuando o algodão, o linho e mais algumas outras como o cânhamo e o rami, são ásperas e resistentes. Por essas características mais brutas, boa parte das fibras vegetais é empregada em aplicações têxteis industriais, acessórios e tapetes. As fibras animais por sua vez, como a lã de ovelha (WO), os pelos de camelídeos como a lã de vicunha e a secreção do bicho-daseda, proporcionam produtos com características ímpares de proteção contra o frio, excelente troca com o ambiente externo, absorção, maciez e leveza. Porém, em virtude da sua obtenção depender de ciclos naturais de produção, são produtos de alto valor comercial, com aplicabilidade praticamente inviável para aplicações em volumes industriais.

$\mathrm{Na}$ comparação entre as fibras naturais e sintéticas Broega (2007), aponta a lã como superior em conforto térmico se comparada à fibra de poliéster, com destaque para higroscopicidade, ou seja, a capacidade de absorção de umidade. Monteiro (2009), destaca que vários institutos de pesquisa e produtores de fibras não naturais investigam, desenvolvem e procuram criar produtos têxteis sejam considerados fisiologicamente adequados.

Além dos fatores já mencionados relativos aos tecidos, outros aspectos do vestuário podem interferir no conforto, quando o usuário está em movimento. O ajuste do vestuário, a quantidade e adequação das aberturas (fechos), acabamentos isolantes de umidade, a espessura e o número de camadas de tecido, também podem prejudicar a mobilidade e a sensação térmica estável.

Quanto às armações ou ligamentos responsáveis pelo entrelaçamento dos fios na tecelagem, o destaque são os tecidos em ligamento sarja, como o denim e a sarja. Esses tecidos, costumeiramente são tecidos com fios de alta 
densidade linear e pela natureza do entrelaçamento, geram tecidos com pontos de ligação bem próximos e fechados. Essa característica confere durabilidade e resistência aos produtos, porém quando combinada a uma modelagem justa no corpo, prejudica a respirabilidade da pele. O resultado é um prejuízo do conforto térmico, que pode ser agravado com uso de fibras mistas como, por exemplo, 50\% algodão e $50 \%$ poliéster ou ampliada no caso de fibras $100 \%$ poliéster.

\section{MATERIAIS E MÉTODOS}

O desenvolvimento desta pesquisa baseou-se no estudo do referencial teórico e na coleta de dados em campo acerca das preferências dos participantes a respeito do toque e da sensação térmica de amostras têxteis comumente utilizadas em uniformes. Para tanto, alguns instrumentos foram desenvolvidos, tais como a cabine de teste, as amostras e os questionários.

O critério utilizado para a seleção das amostras foi baseado na utilização de determinados tecidos pela indústria de uniformes. No teste de campo utilizou-se pares de amostras, totalizando 3 pares. No primeiro teste, a comparação foi entre dois tecidos planos, geralmente utilizados em uniformes sociais - Oxford (poliéster) e Tricoline (algodão). No segundo teste, a comparação foi entre duas malhas, geralmente utilizadas em uniformes para serviços gerais - Piquet (algodão) e Malha PV (poliéster e viscose). No terceiro e último teste, a comparação foi entre duas malhas, geralmente utilizadas em camisetas ou para vestuário esportivo - Meia-malha (algodão) e Malha Dry-fit (poliamida), como visto na Quadro 1. 
Quadro 1. Teste comparativo entre amostras têxteis.

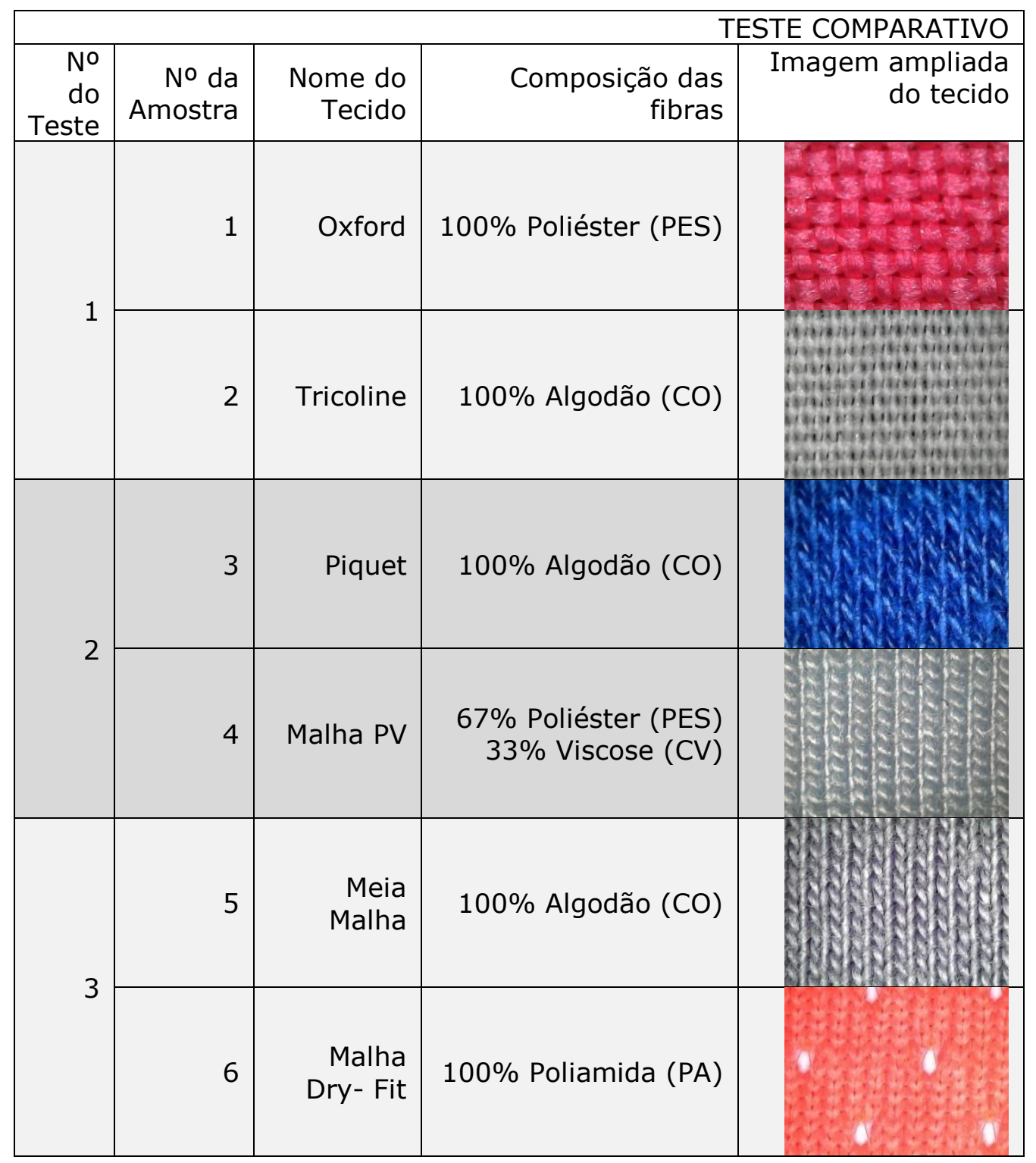

Fonte: elaborado pelos autores.

A pesquisa foi realizada com vinte participantes, de ambos os sexos, com idade entre 18 e 23 anos, nas dependências do Centro de Artes da UDESC. Inicialmente era feita uma breve explanação sobre a proposta do estudo e a apresentação dos instrumentos de coleta. A seguir era solicitado ao participante que tocasse nas amostras têxteis através de uma cabine pela qual só passavam as mãos, impedindo a visualização do material. Durante o teste, eram 
aplicados os questionários sobre as sensações provocadas pelo contato com as amostras. O objetivo foi verificar a percepção de conforto ou desconforto em relação aos materiais têxteis sem a interferência da aparência do material, por meio do toque com as mãos. Essa metodologia baseia-se no estudo realizado por Broega (2007).

\section{Procedimentos}

O primeiro procedimento feito com o participante era o preenchimento da idade do participante. A seguir, foi esclarecido que haveria duas amostras - uma na mão esquerda e outra na direita, seguindo a ordem de como as colunas da tabela se apresentava diante dele. O preenchimento da ficha foi feito por um dos pesquisadores no momento do teste, de modo que o participante não precisasse tirar as mãos de dentro da caixa para responder, conforme Figura 3.

Figura 3. Cabine de teste.

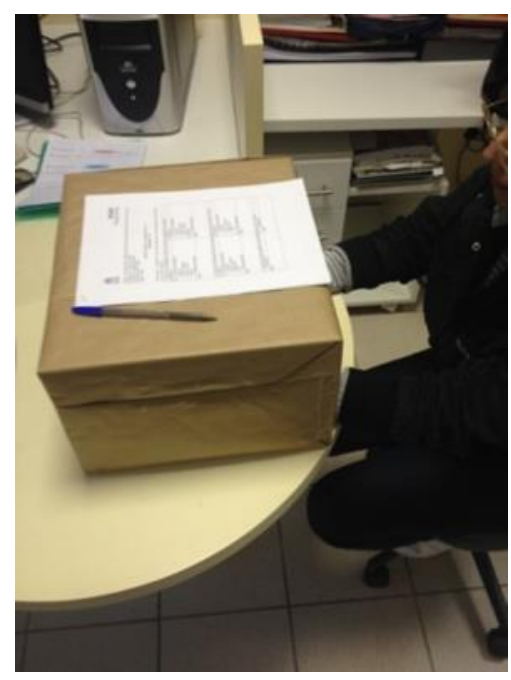

Fonte: Autores (2019). 
Foram utilizados três questionários, um para cada par de amostras. A primeira pergunta era "Qual é a sensação ao toque da mão na superfície do tecido?" As alternativas eram: áspero; muito áspero; muito macio; macio; levemente macio. A segunda pergunta era "Qual é a sensação térmica provocada pelo toque do tecido na mão?" As alternativas eram: quente; muito quente; muito frio; frio; levemente frio. A amostra 1 era entregue na mão esquerda e a amostra 2 na mão direita e as duas questões eram aplicadas tanto na amostra 1 como na 2, como mostra a Figura 4.

Figura 4. Participante com uma amostra em cada mão.

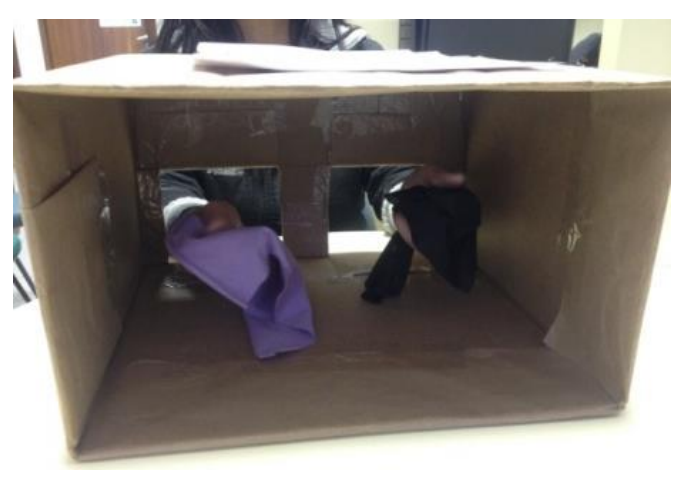

Fonte: Autores (2019).

Para responder a segunda questão, a respeito da sensação térmica, a amostra era presa por um prendedor de roupas em volta da mão do participante. O objetivo era manter o tecido firme junto à pele, uma vez que é desse modo que o material fica em contato com o corpo na forma de vestuário. 
Figura 5. Participante com uma amostra presa na mão.

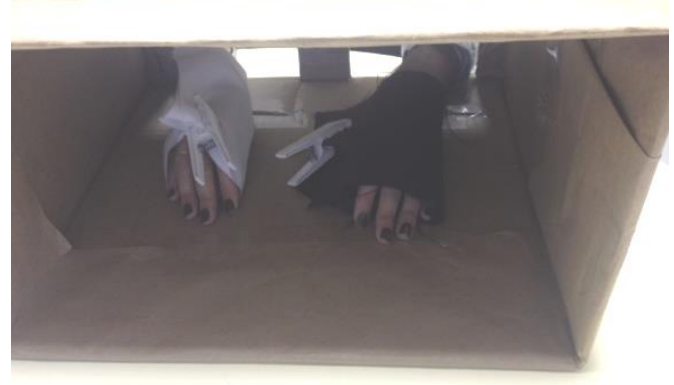

Fonte: Autores (2019).

Para responder a terceira questão, sobre qual seria a amostra preferida na comparação entre uma e outra, as amostras eram soltas e devolvidas a mão do participante. As respostas eram anotadas pela pesquisadora que aplicou 0 teste.

O programa utilizado para o tratamento dos dados da estatística descritiva foi o Microsoft Excel, no qual foram elaboradas seis planilhas, uma para cada amostra. $\mathrm{Na}$ primeira planilha foram registrados os dados referentes à idade dos participantes de modo a verificar a faixa etária dos respondentes - de 18 a 23 - e a média de idade - 20 anos.

Em cada planilha foi registrada a pergunta 1 - "Qual é a sensação ao toque da mão na superfície do tecido?", e a pergunta 2 - "Qual é a sensação térmica provocada pelo toque do tecido na mão?". Ao lado, foram dispostas cada uma das alternativas apresentadas para cada uma delas respectivamente. Em cada planilha foi registrada a pergunta 1 - "Qual é a sensação ao toque da mão na superfície do tecido?", e a pergunta 2 - "Qual é a sensação térmica provocada pelo toque do tecido na mão?". Ao lado, foram 
dispostas cada uma das alternativas apresentadas para cada uma delas respectivamente.

$\mathrm{Na}$ planilha com a segunda amostra de cada teste, foi acrescentada a pergunta sobre a comparação entre as amostras. Desse modo, nas planilhas das amostras de Tricoline, Malha PV e Malha Fit, constava o registro das respostas a respeito da preferência das amostras para uso em ambiente de calor. Depois de feito o registro de todas as 20 respostas em cada planilha foi possível criar os gráficos a partir dos dados.

\section{RESULTADOS}

No teste com a amostra 1 foi utilizado tecido plano comercialmente vendido com o nome de Oxford, ligamento tela e cuja composição é $100 \%$ poliéster (PES). No Questionário Comparativo 1 - Amostra 1, a primeira pergunta feita ao participante era "Qual é a sensação ao toque da mão na superfície do tecido?" As alternativas eram: áspero; muito áspero; muito macio; macio; levemente macio. O resultado mostra que a maioria dos participantes julgou o tecido "levemente áspero" (70\%). A segunda pergunta feita ao participante era "Qual é a sensação térmica provocada pelo toque do tecido na mão?" As alternativas eram: quente; muito quente; muito frio; frio; levemente frio. O resultado mostra que a maioria dos participantes julgou o tecido "quente" (55\%).

No Questionário Comparativo 1 - amostra 2, foi utilizado tecido plano comercialmente vendido com o nome de Tricoline, ligamento tela e cuja composição é 100\% algodão (CO). Na pergunta "Qual é a sensação ao toque da mão na superfície do tecido?", o resultado mostra que a maioria dos participantes julgou o tecido "levemente macio" (50\%) e 
"macio" (20\%). Na pergunta "Qual é a sensação térmica provocada pelo toque do tecido na mão?", o resultado mostra que a maioria dos participantes julgou o tecido "levemente frio" (50\%) e "frio" (40\%).

$\mathrm{Na}$ pergunta final do Questionário Comparativo 1 amostras 1 e 2, o participante deveria escolher entre 0 Oxford e o Tricoline ao responder "Qual das duas amostras você prefere para usar no calor?". O resultado mostra que a maioria dos participantes (90\%) prefere o tecido Tricoline $100 \%$ algodão para usar no calor.

No Questionário Comparativo 2 - amostra 3 foi utilizada malha comercialmente vendida com o nome de Piquet, ligamento piquet e cuja composição é $100 \%$ algodão (CO). No Questionário Comparativo 1 - Amostra 3, na pergunta "Qual é a sensação ao toque da mão na superfície do tecido?", o resultado mostra que a maioria dos participantes julgou o tecido "levemente áspero" (40\%) e "áspero" (20\%). $\mathrm{Na}$ pergunta "Qual é a sensação térmica provocada pelo toque do tecido na mão?", o resultado mostra que a maioria dos participantes julgou o tecido "levemente quente" (50\%) e "quente" (35\%), conforme a imagem 7.

No Questionário Comparativo 2 - amostra 4, foi utilizada malha comercialmente vendida com o nome de Malha PV, ligamento jersey simples e cuja composição é $67 \%$ poliéster (PES) e 33\% viscose (CV). No Questionário Comparativo 2 - Amostra 4, na pergunta "Qual é a sensação ao toque da mão na superfície do tecido?", o resultado mostra que a maioria dos participantes julgou o tecido "muito macio" (60\%). Na pergunta "Qual é a sensação térmica provocada pelo toque do tecido na mão?", o resultado mostra que os participantes estavam divididos entre "levemente frio" (35\%) e "levemente quente" (30\%), com uma leve inclinação ao frio. 
Na pergunta final do Questionário Comparativo 2 amostras 3 e 4, o participante deveria escolher entre a malha Piquet e a Malha PV ao responder "Qual das duas amostras você prefere para usar no calor?". O resultado mostra que a maioria dos participantes (80\%) prefere o tecido Malha PV, cuja composição é $67 \%$ poliéster (PES) e $33 \%$ viscose (CV) para usar no calor, conforme imagem 9.

No Questionário Comparativo 3 - amostra 5 foi utilizada malha comercialmente vendida com o nome de Meia-malha, ligamento Jersey simples e cuja composição é 100\% algodão (CO). Na pergunta "Qual é a sensação ao toque da mão na superfície do tecido?", o resultado mostra que a maioria dos participantes julgou o tecido "macio" (50\%) e "levemente macio" (20\%). Na pergunta "Qual é a sensação térmica provocada pelo toque do tecido na mão?", o resultado mostra que a maioria dos participantes julgou o tecido "levemente quente" (45\%) e "quente" (35\%), conforme a imagem 10.

No Questionário Comparativo 3 - amostra 6, foi utilizada malha comercialmente vendida com o nome de Malha Dryfit, cuja composição é $100 \%$ poliamida (PA). Na pergunta "Qual é a sensação ao toque da mão na superfície do tecido?", o resultado mostra que a maioria dos participantes (90\%) julgou o tecido "muito macio". Na pergunta "Qual é a sensação térmica provocada pelo toque do tecido na mão?", o resultado mostra que os participantes dividiram opiniões entre "frio" (40\%) e "levemente frio" (40\%).

$\mathrm{Na}$ pergunta final do Questionário Comparativo 3 amostras 5 e 6, o participante deveria escolher entre a Meiamalha e a Malha Dry-fit ao responder "Qual das duas amostras você prefere para usar no calor?". O resultado mostra que a totalidade dos participantes (100\%) prefere a 
Malha Dry-fit, cuja composição é $100 \%$ poliamida (PA) para usar no calor.

Ao analisar os resultados pode-se observar que Oxford e Piquet foram considerados ásperos e quentes. A Meia-malha, embora tenha sido considerada como macia, foi tida como quente. Os demais tecidos mesclam opiniões em torno das características de macio e frio, conforme o Quadro 2.

Quadro 2. Resultado do teste comparativo com as amostras têxteis.

\begin{tabular}{|c|c|c|c|c|}
\hline Tecido & Características & Fibra & Toque & $\begin{array}{r}\text { Sensação } \\
\text { térmica }\end{array}$ \\
\hline Oxford & $\begin{array}{r}\text { Plano/ ligamento } \\
\text { tela }\end{array}$ & $\begin{array}{r}100 \% \\
\text { poliéster }\end{array}$ & $\begin{array}{r}\text { Levemente } \\
\text { áspero }\end{array}$ & Quente \\
\hline Tricoline & $\begin{array}{r}\text { Plano/ ligamento } \\
\text { tela }\end{array}$ & $\begin{array}{r}100 \% \\
\text { algodão }\end{array}$ & $\begin{array}{r}\text { Levemente } \\
\text { macio/ macio }\end{array}$ & $\begin{array}{r}\text { Levemente frio/ } \\
\text { frio }\end{array}$ \\
\hline Piquet & $\begin{array}{r}\text { Malha/ligamento } \\
\text { Piquet }\end{array}$ & $\begin{array}{r}100 \% \\
\text { algodão }\end{array}$ & $\begin{array}{r}\text { Levemente } \\
\text { áspero/ áspero }\end{array}$ & $\begin{array}{r}\text { Levemente } \\
\text { quente/quente }\end{array}$ \\
\hline Malha PV & $\begin{array}{r}\text { Malha/ligamento } \\
\text { Jersey simples }\end{array}$ & $\begin{array}{r}67 \% \\
\text { poliéster } \\
33 \% \text { viscose }\end{array}$ & Muito macio & $\begin{array}{r}\text { Levemente } \\
\text { frio/levemente } \\
\text { quente }\end{array}$ \\
\hline $\begin{array}{l}\text { Meia- } \\
\text { malha }\end{array}$ & $\begin{array}{r}\text { Malha/ligamento } \\
\text { Jersey simples }\end{array}$ & $\begin{array}{r}100 \% \\
\text { algodão }\end{array}$ & $\begin{array}{r}\text { Macio/levemente } \\
\text { macio }\end{array}$ & $\begin{array}{r}\text { Levemente } \\
\text { quente/quente }\end{array}$ \\
\hline $\begin{array}{l}\text { Malha } \\
\text { Dry-fit }\end{array}$ & $\begin{array}{l}\text { Malha/ligamento } \\
\text { não identificado }\end{array}$ & $\begin{array}{r}100 \% \\
\text { poliamida }\end{array}$ & Muito macio & $\begin{array}{r}\text { Frio/ levemente } \\
\text { frio }\end{array}$ \\
\hline
\end{tabular}

Fonte: Autores (2019).

Na comparação entre os dois tecidos, o Tricoline foi o preferido pela maioria dos participantes para utilização no calor em detrimento do Oxford. Na comparação entre o Piquet e a Malha PV, a segunda foi preferida, embora os participantes estivessem divididos quanto à sensação térmica. Entretanto, na comparação entre Meia-malha e Malha Dry-fit, os participantes foram unânimes na preferência pela malha de poliamida.

$\mathrm{Na}$ primeira avaliação, o teste foi feito com Oxford e Tricoline. O Oxford possui ligamento tela, que naturalmente trava no toque das mãos e é composto de poliéster. O fato da aspereza relatada se deve ao fato de o tecido não receber 
nenhum beneficiamento que lhe confira sedosidade. As principais características do tecido são 0 baixo amassamento, a durabilidade da cor e o preço baixo. Por essas razões, é muito utilizado em calças e blazers de uniformes sociais para atendentes. O Tricoline também é bastante utilizado, porém para as camisas sociais. Na versão $100 \%$ algodão é mais cômodo e fresco, segundo a preferência dos participantes. Na versão em algodão misto, possivelmente seja mais quente.

Na segunda avaliação, o teste foi feito com duas malhas, o Piquet e a Malha PV. O Piquet é uma malha bastante fechada em função do seu ligamento, e embora seja de algodão a sensação relatada é de calor e aspereza. Por ser o tecido da clássica camisa polo tornou-se uma das malhas mais utilizadas como uniforme profissional. A malha PV também é bastante utilizada em camisetas de uniformes profissionais. Tem um peso leve devido ao seu ligamento em Jersey simples e foi considerada muito macia pelos participantes. Entretanto em relação ao toque térmico dividiu opiniões entre quente e frio. Possivelmente com o usuário em movimento, o tecido seja considerado como quente.

Na terceira avaliação, o teste foi feito com Meia-malha e Malha Dry-fit. A meia-malha é a malha mais utilizadas em camisetas. O determinante é a qualidade dessa malha, que devido ao fio utilizado e aos acabamentos sofridos, pode gerar um produto de maior ou menor valor. A Meia-malha testada era $100 \%$ algodão e foi considerada macia e quente. A Malha Dry-fit, por sua vez, não é utilizada em uniformes profissionais e sim em vestuário esportivo. É comercializado nas versões em fibra de poliamida ou de poliéster e sua principal característica são os pequenos furos que possui entre os pontos da malha, que auxiliam na evaporação do 
calor da pele. Devido à fibra empregada na amostra testada - a poliamida - o tecido torna-se mais caro em relação aos outros. O método de fabricação do fio e o resultado no tecido geram um produto leve e fresco. Por todas essas características, mesmo sem identificar visualmente o tecido, todos os participantes relataram maciez e frescor, além de preferirem unanimemente a amostra de Dry-fit de poliamida para utilização no calor.

A avaliação da preferência dos participantes em relação aos tecidos utilizados em uniformes revela que o tecido preferido não é um tecido comumente encontrado em uniformes e sim para a prática esportiva. O que pode indicar que alguns dos tecidos de uniforme primam pelo custo mais baixo e não pelo conforto do usuário. Assim, uma proposta interessante é emprego de tecidos utilizados em vestuário esportivo, pois estes já possuem a premissa da liberdade de movimentos e do aquecimento do corpo causado pela atividade física.

\section{CONCLUSÕES}

Não há um consenso sobre qual é o melhor método de coleta de dados para avaliação de conforto. No campo de pesquisa em conforto térmico, frequentemente os materiais têxteis são citados como uma variável determinante. Consequentemente o conforto tátil ou de toque na superfície da pele também vem a ser um dado relevante de preferência do usuário.

O vestuário desenvolvido como uniforme, seja profissional, é utilizado sem que o usuário tenha a possibilidade de escolha. Por ser adquirido em quantidade, para utilização por diversas pessoas dentro de uma organização, possui características de padronização. Muitas 
vezes o fator econômico suplanta a usabilidade e a redução de custos acarreta uso de materiais têxteis mais baratos e, consequentemente, menos agradáveis ao usuário.

O desconforto do usuário em relação aos materiais têxteis geralmente é manifestado por meio do incômodo térmico e tátil. Essas sensações ocorrem especialmente após o início de uma atividade física que leve o usuário a sudorese. Ao tocar a pele, o têxtil provoca alguma sensação ao toque, que pode ser aspereza ou maciez, basicamente; a sensação térmica pode ser de frescor ou calor.

Nesse artigo procurou-se submeter a teste de preferência dos usuários tecidos que frequentemente são utilizados em uniformes. O objetivo foi investigar a opinião destes acerca da sensação tátil e térmica do toque dos tecidos e a sua preferência de um deles para uso em uma ocasião de calor ambiente. O resultado pode ajudar a identificar que os tecidos que estão sendo utilizados para a confecção de uniformes profissionais podem prejudicar o conforto dos usuários.

Os materiais testados foram tecidos planos como Oxford e Tricoline e malhas como Piquet, malha PV, meia malha e malha Dry-fit, que são encontrados em uniformes comuns, ou seja, uniformes que não possuem recursos que visam proteção ou desempenho especial nas funções. Como o teste foi às cegas, a variável "preferência do usuário" não influenciou nos resultados, baseando-se apenas na sensação do toque das mãos nas amostras, relatado pelo participante.

No caso do teste 1 , a comparação foi feita entre Oxford e Tricoline. $O$ fato dos participantes preferirem o Tricoline pode ser consequência da fibra do algodão possuir um toque menos seco que o poliéster, mas principalmente em função dos acabamentos sofridos por esse tecido, que the conferem maior maciez. Como o Tricoline é utilizado em camisas e o 
Oxford em calças e blazers, é comum o seu uso em conjunto, o que pode elevar ainda mais o desconforto térmico, especialmente no caso de peças com forro. Não é sugerida uma substituição de um tecido pelo outro, mas o resultado indica uma rejeição do Oxford em ambos os aspectos - tátil e térmico.

No teste 2, a comparação feita entre as malhas Piquet e Malha PV não foi conclusiva em relação ao toque térmico, porém, em relação a maciez a Malha PV foi a preferida. Pelo fato do Pique ser o tecido empregado na clássica camiseta pólo, o fator estético pode influenciar a escolha dos empregadores.

No último teste verficou-se a preferência entre a meia malha e a malha Dry-fit, que vem a ser uma malha utilizada em roupas esportivas e não em uniformes. Essa malha composta de poliamida é leve devido à baixa densidade linear (título), que vem a ser a relação entre o peso do tecido em função da sua metragem. Essa leveza em termos de peso é acentuada pela estrutura intercalada entre os pontos e espaços vazios que permitem a passagem e consequente evaporação do suor durante a atividade física, como observado anteriormente no Quadro 1.

A produção de uniformes vem evoluindo com o passar do tempo e acompanha os avanços na área têxtil e de confecção. Fatores econômicos mantêm no mercado de uniformes produtos de menor qualidade em termos de matéria-prima e acabamentos de modo a proporcionar alternativas economicamente mais atrativas para que as empresas mantenham 0 seu pessoal com 0 visual padronizado. Os resultados deste estudo preliminar apontam uma clara preferência dos participantes pelo tecido utilizado em vestuário esportivo. A leveza e o frescor proporcionado por esse material permitem aos praticantes de atividade 
física uma menor sensação de desconforto após o início das atividades que levam ao aumento da temperatura corporal e sudorese. Assim, torna-se possível suportar melhor o tempo de movimentação do corpo durante a atividade e também a recuperação da condição normal do material após o término desta, uma vez que também tende a secar mais rápido.

Um material que tem uma boa aceitação dos usuários de prática esportiva pode ser útil se utilizado em uniformes para a prática laboral, no sentido de diminuir o desconforto térmico e tátil dos trabalhadores durante as suas atividades diárias. Também pode elevar a produtividade, a satisfação e a qualidade de vida das pessoas, o que traz vantagens para a organização como um todo.

Para estudos futuros é interessante testar os materiais durante a atividade, de modo a verificar o contado do tecido com as partes do corpo mais sensíveis. Também se pode considerar a temperatura ambiente como uma importante variável a ser considerada.

\section{REFERÊNCIAS}

BROEGA, Ana Cristina da Luz. Contribuição para a definição de padrões de conforto de tecidos finos de lã. 2007. $205 \mathrm{f}$. Tese (Doutorado) - Curso de Engenharia Têxtil, Universidade do Minho, Minho, 2007. Disponível em: http://hdl.handle.net/1822/7635. Acesso em: 6 jan. 2019.

DUL, Jan; WEERDMEESTER, Bernard. Ergonomia prática. São Paulo: Edgar Blucher, 2004.GRANDJEAN, Etienne. Manual de ergonomia: adaptando o trabalho ao homem. Porto Alegre: Artes Médicas, 1998.

HAVENITH, George. Thermal Conditions Measurement. In: STANTON, Neville. Handbook of Human Factors and Ergonomics Methods. Boca Raton: Crc Press, 2005. p. 470-485. IIDA, ITIRO. Ergonomia: projeto e produção. São Paulo: Edgard Blücher, 2005.

ISO. ISO 11092:2014(E) - Textiles - Physiological effects Measurement of thermal and water-vapour resistance under steady-s. 
https://www.sis.se/api/document/preview/917737/. Acesso em: 19 maio 2019.

LABAT, Karen L. Human factors as applied in apparel design. In: KARWOWSKI, Waldemar. International Encyclopedia of Ergonomics and Human Factors. 2. ed. Boca Raton: Crc Press/taylor \& Francis Group, 2006. p. 1655-1657. Disponível em: https://books.google.com.br/books?id=Ih-

z6lkTO8EC\&pg $=$ PA $1655 \& \mathrm{lpg}=$ PA1655\&dq $=$ Human + factors + as + ap plied +in +apparel+design\&source $=$ bl\&ots $=0 T s x t p e V j X \& s i g=t L S 2 a 5$ 4 aEmsnHJQOI5a-zepebDI\&hl=pt-

BR\&sa $=$ X\&ved $=2$ ahUKEwjMsuzOnsjfAhXRqZAKHbaYD4wQ6AEwA3 oECAcQAQ\#v=onepage \&q=Human $\% 2$ factors $\% 20$ as $\% 20$ applied $\%$ 20in\%20apparel\%20design\&f=false. Acesso em: 4 dez. 20

MENEGON, Lizandra da Silva. Mensuração de conforto e desconforto em poltrona de aeronave pela teoria da resposta ao item. 2013. 343 f. Tese (Doutorado) - Curso de Engenharia de Produção, Universidade Federal de Santa Catarina, Florianópolis, 2013.2 Disponível em: https://repositorio.ufsc.br/xmlui/handle/123456789/122869.

Acesso em: 21 jan. 2019.

MONTEIRO, Cátia Sofia Neves. Design de Estruturas Têxteis com Elevado Desempenho Fisiológico. 2009. $110 \mathrm{f}$. Dissertação (Mestrado) - Curso de Design de Moda (opção Têxtil), Universidade da Beira Interior, Portugal, 2009. Disponível em: https://ubibliorum.ubi.pt/bitstream/10400.6/1677/1/Disserta\%C3 \%A7\%C3\%A30\%20de\%20mestrado\%20de\%20C\%C3\%A1tia\%20 Monteiro.pdf. Acesso em: 10 ago. 2018.

PEARSON, Elizabeth Jane M.. Comfort and its measurement - A literature review. Disability And Rehabilitation: Assistive Technology, [s.I.], v. 4, n. 5, p.301-310, jan. 2009. Informa UK Limited. Disponível em: http://dx.doi.org/10.1080/17483100902980950. Acesso em: 3 fev. 2019.

SALATA, Ferdinando et al. Dressed for the season: Clothing and outdoor thermal comfort in the Mediterranean population. Building And Environment, [s.I.], v. 146, p.50-63, dez. 2018. Elsevier BV. Disponível em: https://www.sciencedirect.com/science/article/pii/S036013231830 5997. Acesso em: 20 mar. 2019.

SARRAF, Robert Assaad El. Aspectos ergonômicos em uniformes de trabalho. 2004. 149 f. Dissertação (Mestrado) Curso de Mestrado Profissionalizante em Engenharia, Universidade Federal do Rio Grande do Sul, Porto Alegre, 2004. Disponível em: https://lume.ufrgs.br/handle/10183/5666. Acesso em: $10 \mathrm{dez}$. 2018.

TOFTUM, Jørn. Thermal Comfort Indices. In: STANTON, Neville. Handbook of Human Factors and Ergonomics Methods. Boca Raton: Crc Press, 2005. p. 498-508.

WISNER, Alain. Por dentro do trabalho: ergonomia: método \& técnica. São Paulo: Ftd: Oboré, 1987. 